\title{
Personal foreword on Helmut Schwarz Honor Issue ${ }^{\text {is }}$
}

\author{
Jana Roithováa ${ }^{\text {, Maria Schlangen }}{ }^{\mathrm{b}}$, Robert Berger ${ }^{\mathrm{c}}$, Martin Beyer $^{\mathrm{d}, *}$ \\ a Department of Spectroscopy and Catalysis, IMM-Science Faculty, Radboud University, 6500GL Nijmegen, The Netherlands \\ ${ }^{\mathrm{b}}$ Institut für Chemie, Technische Universität Berlin, Strasse des 17. Juni 135, 10623 Berlin, Germany \\ ${ }^{\mathrm{c}}$ Fachbereich Chemie, Philipps-Universität Marburg, Hans-Meerwein-Strasse 4, 35043 Marburg, Germany \\ ${ }^{\mathrm{d}}$ Institut für Ionenphysik und Angewandte Physik, Universität Innsbruck, Technikerstrasse 25, 6020 Innsbruck, Austria
}

\section{A R T I C L E I N F O}

\section{Article history:}

Received 9 October 2018

Accepted 6 November 2018

Available online 15 November 2018

\section{Personal foreword}

Helmut Schwarz has served as Editor in Chief of the International Journal of Mass Spectrometry for incredible 27 years. It was therefore natural to ask Mike Bowers as special issue consultant whether the Journal would publish an issue on the occasion of Helmut's $75^{\text {th }}$ birthday. Mike immediately agreed, and the idea received "unanimous, enthusiastic support from all the remaining editors". Not surprisingly, the large community of colleagues and friends also provided overwhelming response. We received numerous highquality submissions, and cordially thank all contributors for making this Special Issue possible. We are also indebted to Andrea Beck and Irmgard Staud for collecting names and verifying email addresses of potential contributors, as well as to Thomas Weiske for assembling Helmut's list of publications, which is available as supporting information to the Curriculum Vitae.

Like in a baroque fugue, the main theme of the special issue, science and friendship, is introduced by Sason Shaik in his personal essay, and taken up in many personal variations in the dedication lines of the scientific contributions. In our careers, each of us had her or his very personal moment with Helmut, when the distance between the young, ambitious researcher and the eminent professor suddenly disappeared, to be replaced by an unspoken understanding and deep intimacy, born from sharing new ideas and excitement for something special going on. It may look ironic that the long-lasting personal memories connected with an exceedingly eloquent person such as Helmut originate from unspoken, subtle and indirect means of communication. In truth, however, this only underlines his marvelous gift, making strong ties with people and building an extensive network of scientists and friends.

That gift made Helmut Schwarz the perfect cast for highranking, meaning high-work load, positions like Vice President of the German Science Foundation DFG and President of the Alexander von Humboldt Foundation. In both posts, Helmut was not an administrator, but an enthusiastic ambassador of science, making personal ties to politicians and underlining the importance of scientific excellence for society and our modern way of life. This special issue is also a token of appreciation for Helmut's outstanding community service.

Helmut was first reluctant to the idea of celebrating his $75^{\text {th }}$ birthday with a scientific symposium. He finally agreed to a familylike meeting, with talks given by his scientific offspring - students, postdocs and associates. The meeting took place in September 2018 near Innsbruck. It turned into a celebration of Helmut's key concepts: doing science for the joy of discovery, for the intellectual challenges provided by nature, and, last but not least, for the interaction with students and colleagues, who turn into friends.

This brings us back to the theme of the special issue: Helmut, we wish you many more years in good health for actively engaging in science and friendship, and for enjoying the love of your family.

\footnotetext{
is Virtual Special Issue of the International Journal of Mass Spectrometry. See https://www.sciencedirect.com/journal/international-journal-of-massspectrometry/special-issue/10WK91ZBR5N

* Corresponding author.

E-mail address: beyer@uibk.ac.at (M. Beyer).
} 


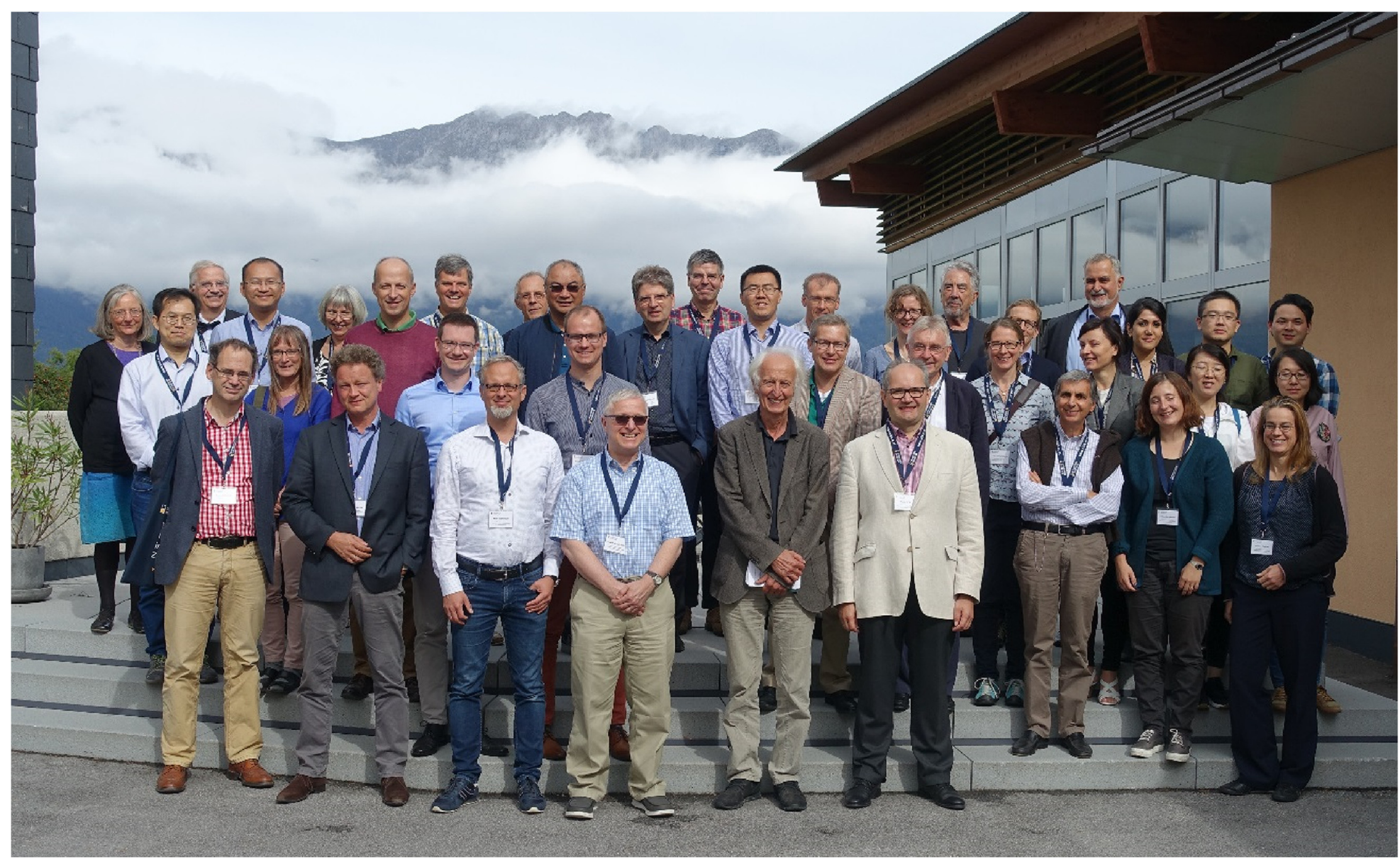

Ion Chemistry and Catalysis - Scientific Symposium in Honor of Prof. Dr. Drs. h.c. mult. Helmut Schwarz on the Occasion of his 75 $5^{\text {th }}$ Birthday. September 21-22, 2018, Tiroler Bildunginstitut - Grillhof, Vill. With generous support from the Vice Rector of Research of the University of Innsbruck. 